\title{
Evaluation of a school-based physical activity intervention in Alexandra Township
}

\author{
Catherine E Draper (PhD) ${ }^{1}$ \\ Lauren de Kock (MA) ${ }^{2}$ \\ Anna T Grimsrud (MPH) ${ }^{1}$ \\ Michael Rudolph (MPH, MSc, Specialist in Community Dentistry) ${ }^{2}$ \\ Simon Nemutandani (MPH, MChD) ${ }^{2}$ \\ Tracy Kolbe-Alexander (PhD) ${ }^{1}$ \\ Estelle V Lambert (PhD) ${ }^{1}$ \\ ${ }^{1}$ UCT/MRC Research Unit for Exercise Science and Sports Medicine, Department of Human Biology, Faculty of Health Sciences, \\ University of Cape Town \\ ${ }^{2}$ Health Promotions Unit, School of Public Heath, University of the Witwatersrand, Johannesburg
}

\begin{abstract}
Objectives. Non-communicable diseases and limited participation in school physical education have become increasing concerns in South Africa. In response to these concerns, a schoolbased physical activity intervention, Healthnutz, was implemented in three primary schools in Alexandra Township, Johannesburg. Evaluation of Healthnutz included assessing its feasibility and acceptability, and short-term changes in learners' physical fitness, knowledge and attitudes.

Methods. To assess feasibility and acceptability, a situational analysis and focus groups with teachers and programme monitors were conducted. Pre-post fitness testing (3-month interval) was conducted with learners, and a questionnaire assessed changes in learners' knowledge, attitudes, self-efficacy, and perceived barriers to physical activity, in control and intervention schools.

Results. At implementation, teachers identified the need for more physical activity in the school environment and were positive about Healthnutz. Follow-up focus group discussions suggested that it was positively impacting teachers, learners and the school in general. Scores for sit and reach $(p<0.001)$, sit ups $(p<0.02)$ and shuttle run $(p<0.0001)$ improved significantly in in-
\end{abstract}

\section{CORRESPONDENCE:}

Dr Catherine Draper

UCT/MRC Research Unit for Exercise Science and Sports

Medicine

Sports Science Institute of South Africa

Boundary Road

Newlands

7700 Cape Town

Tel: +27216504570

E-mail: catherine.draper@uct.ac.za tervention but not control schools. A significant decrease was observed in learners' perceived external barriers to physical activity $(p<0.0001)$ along with a positive change in learners' self-efficacy for physical activity $(p<0.05)$.

Conclusions. Healthnutz raised awareness of the importance of physical activity in intervention schools. Findings indicate that even limited exposure to a physical activity intervention can lead to a significant improvement in aspects of learners' fitness, knowledge, attitudes and perceptions regarding physical activity. Furthermore, training and support of teachers needs to be nonjudgemental and empowering.

\section{Introduction}

Non-communicable diseases (NCDs) have become an increasing concern in South Africa. ${ }^{1}$ Despite the apparent rise of NCDs ${ }^{2}$ and the alarming prevalence of both obesity and physical inactivity in South Africans, ${ }^{3}$ even from more disadvantaged communities, ${ }^{4}$ there are limited data on successful physical activity interventions in preventing and reducing NCDs in these settings. Physical activity has been linked to the prevention and reduction of these diseases, ${ }^{5}$ and the problem of inactivity has been demonstrated throughout the life-course in South Africans, with only $50 \%$ of South African secondary school learners reporting participation in weekly physical education. ${ }^{6}$

School-based physical activity interventions are one of the many strategies employed in both developed and developing settings to address the rise of NCDs, ${ }^{7,8}$ although there is limited literature from developing settings. Within school-based interventions, teachers play a pivotal role in the implementation of these interventions and are acknowledged as an important source of information regarding perceptions of barriers to and factors facilitating school-based physical activity interventions ${ }^{9}$ and the promotion of physical activity in the school environment. ${ }^{10}$ 


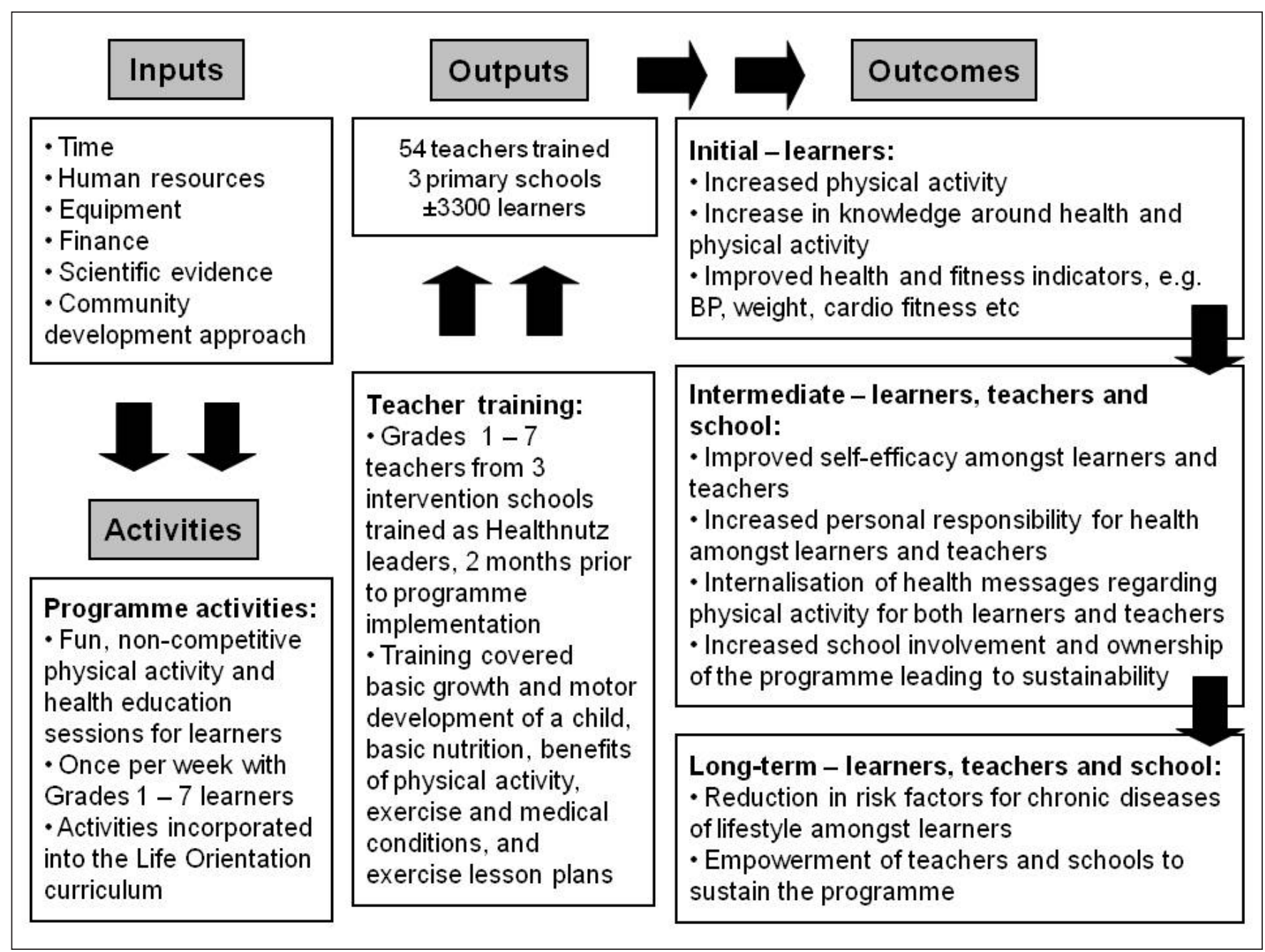

Fig.1. The Healthnutz model.

\section{The Discovery Healthy Lifestyle Programme}

The Discovery Healthy Lifestyle Programme (DHLP), a corporate social investment project from a major national private health insurer, was developed in 2006 as a national pilot project of the Community Health Intervention Programmes (CHIPs). ${ }^{11}$ Healthnutz (Fig. 1), one of the CHIPs' interventions for primary (elementary) schools, was developed in response to the reality that physical education in South Africa was reformulated in 2004, to be delivered by classroom teachers as part of an integrated curriculum. The DHLP programme was specifically designed to support teachers in incorporating physical activity and nutrition education into the life orientation (LO) curriculum, into which these topics were placed.

Alexandra Township ('Alex') located in Johannesburg, Gauteng Province, was selected as one of the urban pilot communities for the DHLP. Community concerns in Alex include overcrowding, poor sanitation, high levels of crime and violence, unemployment, poverty, substance abuse, and an estimated HIV/AIDS prevalence of $40 \%{ }^{12,13}$ Three primary schools in Alex were purposively selected by the Gauteng Department of Education as Healthnutz intervention schools, and three control schools were recruited.

\section{Evaluation aims}

Evaluation of Healthnutz included assessing its feasibility and acceptability in schools, along with changes in physical fitness, knowledge and attitudes of the learners.

\section{Methods}

\section{Situational analysis}

The situational analysis was done on the physical activity environment of each intervention school (May 2006), which involved a combination of direct observation and consultation during school time with a member of the school staff. This was carried out using a quantitative tool developed for use in South African schools, with specific focus on implementation of physical activity and sport in the timetable, the availability of sporting equipment and facilities, and the distribution and accessibility of healthy food within the school. Owing to difficulties in recruiting control schools, the situational analysis was not carried out at these schools.

\section{Focus groups}

A total of five focus groups were conducted (in English) pre- and 6 months post-implementation (May and November 2006). Participants in the focus groups were teachers $(N=39)$ and programme monitors $(N=2)$. For the pre-implementation focus group $(N=10)$, each school was asked to request participation of four teachers who had undergone Healthnutz training. All teachers who had been involved in implementing the Healthnutz programme were asked to participate in the post-implementation focus groups $(N=8, N=16$, $N=5$ ). The teacher questionnaire was distributed to all teachers at intervention schools; 38 completed questionnaires were returned ( $46 \%$ response rate). 
Notes of the group discussion were taken by two facilitators as recording via audio or video may have inhibited discussion (it was the first meeting between the research team and teachers). Notes were taken during the three post-implementation focus groups, and based on the relationship established with teachers, these were recorded via audio. At the same time, a focus group was conducted with the programme monitors. Topics for the initial focus group with teachers covered the following:

- relative importance of physical activity

- perceptions of and expectations about Healthnutz, including training

- factors that could enable or hinder the success of Healthnutz.

Post-implementation focus groups with the teachers covered the following:

- Healthnutz implementation in their school

- strengths or limitations as Healthnutz leaders

- general impact of Healthnutz on school environment, learners, teachers and community.

The focus group with the programme monitors addressed the following:

- relationship with schools, CHIPs, and the research team

- strengths and weaknesses of Healthnutz

- enabling factors and barriers to Healthnutz implementation.

Summaries of the focus group discussions were generated and these, along with summaries of the first focus group, were circulated to other members of the research team for verification and approval. The topics mentioned above served as a framework for the analysis of the focus group summaries, which was done using a qualitative content analytic approach.

\section{Teacher questionnaire}

A questionnaire was used for the formative assessment of teachers, and was distributed to the teachers one month after programme implementation. Questions were asked about the following:

- demographic and professional information

- views on physical activity and the curriculum

- personal lifestyle risk profiles.

\section{Learners: fitness testing and questionnaire}

All learners participating in this study were in grades 4,5 and 6 from the three intervention schools $(N=423)$ and two control schools $(N=85)$. The low number of learners at control schools was attributable to scheduling conflicts. Learner fitness testing was conducted at all five schools pre- and 4 months post-implementation (July and November 2006) using the Eurofit Fitness Testing protocol ${ }^{14}$ which has been adapted for use in a South African setting, ${ }^{15}$ and comprised the following:

- sit and reach (flexibility)

- cricket ball throw (upper body strength)

- standing long jump (lower body strength)

- sit-ups (abdominal strength)

- 10 metre shuttle run (cardiovascular fitness)

- height and weight.
A physical activity questionnaire was administered in a group setting at the intervention and control schools with the assistance of local trained fieldworkers who were fluent in the main languages spoken by learners. This questionnaire, developed by the research team, was based on validated questionnaires that have been used in other similar studies with grade 4 - 6 learners and was piloted in a similar setting in Cape Town. The questionnaire included questions on the following:

- sociodemographics, such as living conditions and home language

- physical activity behaviour

- sedentary behaviour

- knowledge and gender attitudes regarding physical activity

- perceived barriers to physical activity

- exposure to physical activity messages.

Repeated measures analyses of variance (Statistica V8; Statsoft, Tulsa, OK, USA, Sigma-restricted parameterisation) were used to analyse changes in fitness measures, as well as height and weight. With regards to learners' questionnaire responses, a score was given for each affirmative response. These scores (all related to physical activity) were grouped into the following: external barriers, self-efficacy, knowledge and gender attitudes. Parametric and nonparametric (Mann-Whitney $U$ Test) statistics were performed on the changes in these scores, pre and post.

Ethical approval for this research was obtained from the Research Ethics Committee in the Faculty of Health Sciences, University of Cape Town (REC REF: 486/2005). Permission to conduct this research was obtained from the Gauteng Department of Education. Parental consent (written) was obtained for all the learners involved.

\section{Results}

\section{School environment}

Key results from the situational analysis of the schools' physical activity environment are presented in Table I. The three intervention schools were situated in different locations in Alexandra, leading to disparity in availability of resources. Two schools had a surplus of new sporting equipment that had been donated approximately 6 months earlier (some of which was for sports not commonly played in this area, such as baseball and badminton), and were located directly adjacent to accessible community sports facilities. In addition, there was sufficient space for physical activity, although the surface of these spaces was generally concrete or tar. The third school, located in a more densely populated part of Alexandra, had very little space between classrooms, minimal sporting equipment and was further away from community sports facilities.

During one of the focus groups with teachers, the importance of support for Healthnutz-trained teachers was emphasised. Based on their past experience with other school interventions, teachers highlighted that assistance from Healthnutz monitors should focus on encouragement and recognition rather than on criticism and disapproval. Thus, a fear of being criticised for not using the equipment correctly may have prevented teachers from making use of any new equipment.

\section{Pre-implementation focus groups: teachers}

The discussion revealed that as physical activity is only one component of the life orientation curriculum, it has been allocated far less 
time in the curriculum and only a small percentage of teachers are involved. Teachers expressed concern that children had become less active in recent years and reported that the number of overweight children had increased, but saw this problem alongside undernourished learners who rely on the school feeding scheme. Furthermore, they spoke of limited opportunities for learners to be physically active in Alexandra, due to space constraints, a lack of facilities and safety. Teachers were aware that they themselves were overweight as a result of inactivity and poor dietary habits, and acknowledged the importance of their position as role models for healthy lifestyles for the learners.

Due to the identified need for more physical activity in the school environment, teachers were positive about the Healthnutz programme and training they received. They expressed confidence in its successful implementation, despite some concerns about how it would fit into their already busy timetable. Teachers were able to identify a wide range of possible benefits of the programme for themselves and the learners. These included the promotion of healthy lifestyles and increased awareness of the importance of physical activity. With specific reference to learners, the benefits included both health and psychosocial outcomes, such as discipline, keeping out of trouble, and enjoyment. Even at this stage of implementation, it seemed clear that the Healthnutz programme had raised awareness about the importance of physical activity and healthy lifestyles.

'Children in our school used to eat junk food. But since we've introduced this, they know how to choose the best food....after break they used to have this plastic [bag] with yellow chips and whatever, but since then it has reduced, and the sweets as well...we encourage them to buy fruit and we also talk to the vendors to sell fruits to them...they come to you to show you, because you show them that you can afford an apple or whatever a day...and they come and show you "I've bought this"'(Teacher).

\section{Follow-up focus groups: teachers}

The follow-up focus groups with teachers painted a rather complex picture of the implementation process, and it is worth noting that environmental differences between schools mentioned previously did not appear to have an impact on the perceptions of teachers from the three intervention schools.

Reviewing the teachers' impressions of the impact of the programme on the school, it appeared that the programme was being implemented as intended. Teachers reported that their schools had become healthier environments due to raised awareness and some environmental changes relating to nutrition. These changes included vendors selling fruit to learners in addition to their usual fare of highly processed, high fat, savoury or sweet foods. Teachers expressed feelings of improved health and self-efficacy regarding their own activity levels. One teacher commented that the programme had helped to improve relationships between learners and teachers.

'I think the relations with the learners and the teachers sometimes improved with this programme. You find that some of the learners are so scared of the teachers, but once you do with them the Healthnutz programme, they find you being friendly, and the ice starts to melt.' (Teacher).

The positive impact of the programme activities on the learners was also noticeable to teachers, and learners were reported to enjoy the activities. Teachers believed that the healthy eating component of Healthnutz was well received, with learners making healthier food choices. Teachers from one school commented that the healthy lifestyle message was also reaching the learners' parents and caregivers.

'What you teach them, they pass on to their parents, which is a very good thing...you hear a mother saying "Hey, my child was saying this about food and that and that..." They also remind us, "Teacher, you are eating this and this, but you said we shouldn't"...I changed my eating habits, and I used to like coke, and [trainer's name] discouraged a lot us from drinking a lot of coke [Coca Cola]. He's saying like even if you can take it and put it in the car's battery... so I'm starting to drink more water.' (Teacher).

However, it was quite clear from the focus group discussions that the programme had many implementation challenges. In addition to the difficulty of fitting Healthnutz into the timetable, many of the obstacles related to teachers. These included the loss of teachers who were trained in Healthnutz (either no longer taught LO or left the school), lack of motivation among some teachers who were trained but did not implement the programme, teachers who were implementing Healthnutz without training, and teachers lacking confidence to direct activities. This lack of confidence could have been due to the teachers themselves being overweight and inactive. Teachers also mentioned having difficulty in controlling big groups of learners and maintained that there was not sufficient equipment and/or space.

'It's mixed with the teachers. There's those who are keen on it, there are those who want to do it because they are also aware of the benefits that physical activity would have on a child's life, on their life as well. There are those who are just saying "this is extra work for me, l'd rather not get too involved". Some of the teachers, they are very reluctant. And also the timetable... almost all of the schools

\section{TABLE I. Situational analysis of the physical activity environment}

\begin{tabular}{|c|c|c|c|}
\hline & Intervention school 1 & Intervention school 2 & Intervention school 3 \\
\hline Learners & 1187 & 1051 & 1024 \\
\hline Teachers & 29 & 28 & 25 \\
\hline Learner / teacher ratio & 41 & 38 & 41 \\
\hline Facilities $^{*}$ & 4 playgrounds (paved/cement) & $\begin{array}{l}2 \text { playgrounds (paved/cement) } \\
\text { soccer field, hall }\end{array}$ & $\begin{array}{l}1 \text { playground (paved/ } \\
\text { cement) }\end{array}$ \\
\hline Equipment & $\begin{array}{l}\text { Rugby balls, tennis balls, soccer balls, } \\
\text { netballs, beacons, cricket wickets, } \\
\text { cricket bats and pads, frisbee, } \\
\text { plastic bats, clipboard, whistles, scales }\end{array}$ & $\begin{array}{l}\text { Complete cricket kit (pads, gloves, } \\
\text { balls, wickets, bats), complete softball kit } \\
\text { (helmets, mits, balls, bats), cones, } \\
\text { tennis balls and racquets, rugby balls }\end{array}$ & Sports kit, cricket kit \\
\hline
\end{tabular}




\begin{tabular}{ll}
\hline TABLE II. Teacher questionnaire results & Yes \\
\hline Views on physical activity and the curriculum & $29 \%$ \\
Believe that physical activity and nutrition are catered for in the curriculum & $45 \%$ \\
Feel adequately trained to teach physical activity and nutrition & $82 \%$ \\
Feel that physical activity should be part of Life Orientation & $63 \%$ \\
Main barriers to physical activity & $50 \%$ \\
School lacks facilities & $68 \%$ \\
School lacks equipment & \\
Learners can't afford shoes or kit & $18 \%$ \\
Lifestyle habits and health & $53 \%$ \\
I eat fresh fruit and vegetables daily, and only eat unhealthy foods very occasionally or not at all & $13 \%$ \\
I maintain a good balance in my diet by eating foods like fresh fruit and vegetables but I also eat unhealthy foods a fair amount & $50 \%$ \\
I don't eat enough healthy foods like fresh fruit and vegetables but I intend to get a better balance in my diet over the next 12 months & $16 \%$ \\
Unhappy or unsatisfied with their weight & $42 \%$ \\
I try to exercise several times each week & $34 \%$ \\
I exercise only occasionally or not at all but I intend to start doing more from now on & $45 \%$ \\
Rate their general state of health as fair & \\
Rate their general state of health as good &
\end{tabular}

complain about the timetable, it clashes with their own timetable.' (Monitor).

'Using of the equipment...they don't use the equipment at all...some of them, not all of them, some of them, they don't use the equipment. That might go with the confidence of some of the teachers, as you said, that they want to have [programme monitor's name] there, they want to have [programme monitor's name] there, to start them off and things. So maybe that might be the reason that most of the teachers they don't think they can be able to do it without assistance. That might be one of the issues. They don't even want to use the equipment. They'd rather have the kids run around and jumping and skipping than for them to do more sports skills.' (Monitor)

\section{Follow-up focus groups: monitors}

The monitors' involvement with the Healthnutz programme (from the initial training to implementation and assistance with evaluation) enabled them to provide an overall perspective of the programme that was likely to be more objective than the teachers' point of view. Monitors' perceptions on the implementation of Healthnutz did not differ between the 3 schools, and they described a range of attitudes of teachers which varied from the more passionate, often younger ones acting as role models for the learners, to those who wanted the monitors to do everything for them. These teachers were not motivated to implement the programme, even though they participated in the training. The monitors suggested that some teachers participated in the training simply because it gave them a break from school and that there was an incentive for them to get a free t-shirt and certificate.

Furthermore, monitors felt that some teachers perceived the programme as extra work and were resistant to change. The monitors felt that teachers had sufficient equipment for Healthnutz and that group sizes were manageable. They argued that these factors should not have inhibited them from implementing the programme.

Lack of confidence was also raised by the monitors. They suggested that teachers may be afraid to make mistakes, especially if these would be recorded as part of a 'bad' report by the monitors. The role of the monitors was described by some teachers as helpful, supportive and encouraging while others saw them as 'assessors' whose role was to judge their performance; thus some teachers referred to the monitors' visits, as 'assessments'. These differences in perception may have resulted in the monitors' visits causing 'performance anxiety' instead of boosting confidence which they sorely needed.

'Some of them...that's why they're very reluctant, because when we are there, they think that we are there to write bad report about them. Because some of them, they don't exactly know the actual steps of conducting a session. So when they make mistakes, they feel like there's something that...they think we are going to write about them when we submit our reports. That's why are very reluctant...always want us to conduct a session. I think that's the reason. Because when we go there we usually have some note book to take some notes, like what kind of exercise does the teacher do, and also what kind of warm-ups, so we take some notes. ' (Monitor).

\section{Questionnaire: teachers}

Results from the teachers' questionnaire are presented in Table II.

\section{Fitness testing: learners}

Pre-post fitness testing results for learners are presented in Table III. For sit-and-reach, scores in the control group decreased from prepost whereas they increased significantly in the intervention group $(p<0.001)$. Baseline sit-and-reach scores, however, were higher in the control group. These results were adjusted for the potential confounding variable of gender. Sit-up scores also improved significantly in the intervention group, whereas there was no significant improvement in sit-up scores in the control group $(p<0.02)$. Learners from intervention schools also had significantly faster shuttle run scores following the intervention; this was not demonstrated in the control group $(p<0.0001)$. In both groups, long jump $(p<0.0001)$ and ball throw $(p<0.002)$ scores increased from pre- to post-intervention. There were no effects of the intervention on these scores.

\section{Questionnaire: learners}

Table IV outlines learners' questionnaire responses for external barriers to and self-efficacy for physical activity, as well as knowledge of and gender attitudes towards participation in physical activity. There 


\begin{tabular}{|c|c|c|c|c|c|c|c|}
\hline Outcome variable & Intervention / control & $N$ & Pre: mean & Pre: SD & Post: mean & Post: SD & $\begin{array}{l}p \text {-value } \\
\text { for group } \\
x \text { time } \\
\text { interaction }\end{array}$ \\
\hline \multirow[t]{5}{*}{ Height (cm) } & Control & 8 & 142.4 & \pm 8.5 & 144.9 & \pm 9.9 & $p=0.602$ \\
\hline & & 1 & & & & & \\
\hline & Intervention & 4 & 142.9 & \pm 8.4 & 145.2 & \pm 9 & \\
\hline & & 2 & & & & & \\
\hline & & 2 & & & & & \\
\hline \multirow[t]{5}{*}{ Weight (kg) } & Control & 8 & 36.9 & \pm 8.4 & 37.1 & \pm 8.4 & $p<0.005$ \\
\hline & & 5 & & & & & \\
\hline & Intervention & 4 & 35.8 & \pm 8.6 & 37.1 & \pm 8.7 & \\
\hline & & 2 & & & & & \\
\hline & & 3 & & & & & \\
\hline \multirow[t]{5}{*}{ Sit and reach $(\mathrm{cm})$} & Control & 8 & 24.5 & \pm 16 & 14 & \pm 9.7 & $p<0.001$ \\
\hline & & 3 & & & & & \\
\hline & Intervention & 4 & 14.6 & \pm 5.9 & 19 & \pm 6.8 & \\
\hline & & 1 & & & & & \\
\hline & & 0 & & & & & \\
\hline \multirow[t]{5}{*}{ Sit ups (in 30 seconds) } & Control & 8 & 15.2 & \pm 5.4 & 15.5 & \pm 5.1 & $p<0.02$ \\
\hline & & 3 & & & & & \\
\hline & Intervention & 4 & 16 & \pm 6 & 17.8 & \pm 6.1 & \\
\hline & & 2 & & & & & \\
\hline & & 6 & & & & & \\
\hline \multirow[t]{5}{*}{ Shuttle run (seconds) } & Control & 8 & 47.2 & \pm 4.6 & 48.6 & \pm 5.5 & $p<0.0001$ \\
\hline & & 3 & & & & & \\
\hline & Intervention & 4 & 48.5 & \pm 5.1 & 46.2 & \pm 4.6 & \\
\hline & & 0 & & & & & \\
\hline & & 5 & & & & & \\
\hline \multirow[t]{5}{*}{ Long jump (cm) } & Control & 8 & 120.4 & \pm 18.8 & 135 & \pm 19.7 & $p=0.135$ \\
\hline & & 4 & & & & & \\
\hline & Intervention & 4 & 124.6 & \pm 25.7 & 134.3 & \pm 25.7 & \\
\hline & & 0 & & & & & \\
\hline & & 9 & & & & & \\
\hline \multirow[t]{5}{*}{ Ball throw $(m)$} & Control & 8 & 21.7 & \pm 6.2 & 21.8 & \pm 6.9 & $p=0.106$ \\
\hline & & 5 & & & & & \\
\hline & Intervention & 4 & 22 & \pm 7.2 & 23.1 & \pm 7.5 & \\
\hline & & 1 & & & & & \\
\hline & & 3 & & & & & \\
\hline
\end{tabular}

was a significant lowering of perceived external barriers to physical activity in the intervention but not the control group $(p<0.0001)$. Similarly, learners from intervention schools experienced a positive change in self-efficacy for physical activity $(p<0.05)$, not demonstrated in the control group. The interpretation was not different, irrespective of whether results were analysed using non-parametric or parametric analyses, and gender did not influence these results.
Knowledge concerning physical activity increased similarly in both the intervention and control groups. However, learners in the intervention group showed an improvement in gender attitudes towards participation in physical activity, not demonstrated by the control group $(p<0.001)$. 


\section{TABLE IV. Learner questionnaire results}

\section{Perceived external barriers to physical activity*}

For me, it is too dangerous to walk to school or play outside

For me, it is too far to walk to school

There is no place outside to play near my home or school

I am not allowed to stay after school to play sports

External barriers change score

Mean differences (SD)

$p$-value for between group differences

\section{Self-efficacy for physical activity*}

I do not have enough time to do sport or play games with my friends

I have fun when I am doing physical activity

I can do physical activity that makes me sweat and breath hard

I get tired very quickly when I do physical activity

Self-efficacy change score

Mean differences (SD)

$p$-value for between group differences

\section{Physical activity knowledge**}

You are doing physical activity when you are playing sport, running or going to the gym

You are doing physical activity when you play games with your friends, e.g. skipping, other traditional games 72

Walking is physical activity, e.g. walking to / walking home from school

Doing chores at home, e.g. fetching water, chopping wood, is physical activity

Dancing is physical activity

It is important to do physical activity in order to keep my body healthy

I should do at least 30 minutes of physical activity every day

Knowledge $t$-test scores $(p=0.76)$

Mean differences (SD)

$p$-value for between group differences

\section{Gender attitudes towards participation in physical activity**}

Boys are better at physical activity than girls

Girls should not sweat and breathe hard when they do physically activity

Gender attitude t-test scores $(p<0.001)$

Mean differences (SD)

$p$-value for between group differences

*\% who answered 'yes'

** \% who answered 'true'

\section{Discussion}

The findings of this evaluation demonstrate that Healthnutz was largely implemented as intended and that the implementation of Healthnutz in these schools was perceived as meaningful and useful by the teachers. According to teachers, it has raised awareness in teachers, learners and parents of the importance of physical activ-

\begin{tabular}{lllll}
\multicolumn{2}{c}{ Intervention } & & \multicolumn{2}{c}{ Control } \\
\cline { 5 - 5 } \cline { 5 - 5 } Pre & Post & & Pre & Post \\
$31 \%$ & $27 \%$ & & $39 \%$ & $33 \%$ \\
$31 \%$ & $31 \%$ & & $52 \%$ & $60 \%$ \\
$62 \%$ & $35 \%$ & & $47 \%$ & $43 \%$ \\
$48 \%$ & $30 \%$ & & $47 \%$ & $45 \%$ \\
Intervention & & \multicolumn{2}{c}{ Control } \\
$-0.57(1.28)$ & & $0.12(1.3)$ \\
$p<0.001$ & & \multicolumn{2}{c}{}
\end{tabular}

$p<0.001$

\begin{tabular}{lrrrr}
\multicolumn{2}{c}{ Intervention } & & \multicolumn{2}{c}{ Control } \\
\cline { 1 - 1 } \cline { 5 - 5 } Pre & Post & & Pre & Post \\
$52 \%$ & $36 \%$ & & $43 \%$ & $42 \%$ \\
$84 \%$ & $86 \%$ & & $77 \%$ & $87 \%$ \\
$55 \%$ & $66 \%$ & & $57 \%$ & $68 \%$ \\
$34 \%$ & $35 \%$ & & $47 \%$ & $45 \%$ \\
Intervention & & \multicolumn{2}{c}{ Control } \\
$0.3(1.29)$ & & & -0.01 & $(1.19)$ \\
$p<0.05$ & & &
\end{tabular}

Intervention

Pre Post Pre Post

$61 \% \quad 65 \% \quad 57 \% \quad 70 \%$

$72 \% \quad 75 \% \quad 66 \% \quad 71 \%$

$57 \% \quad 66 \% \quad 61 \% \quad 68 \%$

$47 \% \quad 51 \% \quad 46 \% \quad 51 \%$

$63 \% \quad 68 \% \quad 66 \% \quad 71 \%$

$89 \% \quad 90 \% \quad 86 \% \quad 87 \%$

$59 \% \quad 62 \% \quad 55 \% \quad 47 \%$

Intervention Control

$0.56(2.33) \quad 0.47(2.11)$

$p=0.76$

\begin{tabular}{lrrrr}
\multicolumn{2}{c}{ Intervention } & & \multicolumn{2}{c}{ Control } \\
\cline { 1 - 2 } Pre & Post & & Pre & Post \\
$49 \%$ & $49 \%$ & & $56 \%$ & $48 \%$ \\
$38 \%$ & $28 \%$ & & $25 \%$ & $21 \%$ \\
Intervention & & \multicolumn{2}{c}{ Control } \\
$-0.34(1.34)$ & & $0.27(1.31)$ \\
$p<0.001$ & & &
\end{tabular}

ity, alongside competing health and social priorities, indicating that the Healthnutz programme is an acceptable programme for these schools. The schools, principals and the Department of Education seemed willing to incorporate more physical activity into their school environment and curriculum, even with its additional demands on the teachers and time in the school day. The questionnaire results from teachers validate the qualitative findings and highlight the need for 
an intervention that capacitates teachers within LO, and that takes into account the substantial barriers to physical activity relating to resources. Teachers' responses regarding their state of health further emphasises the need for them to be included in any health promotion endeavours within the school environment.

Many of these findings are comparable with findings from other similar studies that have highlighted the importance of stakeholder involvement, a supportive school environment, effective training of teachers, and programme alignment with existing curricula., ${ }^{7,8}$ Challenges included teacher constraints, both in terms of time and other responsibilities, and getting teachers involved. $7,9,16,17$ Physical barriers mentioned by teachers in this study, such as learners not having the appropriate clothing for physical activity, ${ }^{7}$ space constraints, ${ }^{16,17}$ limited facilities and equipment, limited funds and difficulty controlling big classes ${ }^{17}$ are also common challenges experienced amongst those implementing school-based physical activity interventions

Results for learners indicate that limited (4 months) exposure to a physical activity intervention can make a significant impact on fitness, knowledge and gender attitudes regarding physical activity. In addition, the results relating to external barriers to and self-efficacy for physical activity are encouraging as they show that perceptions of physical activity were open to change even when external circumstances remained the same. Few other intervention studies report significant changes such as these after such limited exposure. The majority of these studies demonstrate changes as a result of interventions lasting in the region of a year for cardiovascular fitness ${ }^{18}$ and psychosocial measures, ${ }^{19}$ but sometimes up to 3 years for psychosocial variables. ${ }^{20}$

Limitations of this study include the lack of rigorous monitoring data to support the evaluation, limited data collected from contro schools, and the small number of learners tested at control schools. This study would have also benefited from more in-depth qualitative investigation as well as a longer exposure to Healthnutz. Future research could include assessment of the long-term sustainability of the programme in these schools. Follow-up visits to these schools revealed that while the programme is no longer being implemented as originally intended (incorporated into the Life Orientation curriculum), there may well have been changes in the physical activity culture of these schools. Future research would do well to investigate these changes.

\section{Implications of findings}

These findings highlight that challenges and constraints in the school environment are similar in both developed and developing settings. In schools where resources are limited and where available resources are allocated to other school and community concerns taking precedence over healthy lifestyles, those promoting health in the school environment need to prioritise collaboration between public health care practitioners and key stakeholders in schools and communities. This is in order to not only effectively monitor and evaluate interventions in the school environment, but also to keep healthy lifestyles high on the school agenda.

Regarding the inclusion of teachers in school-based interventions, the process of recruiting, training and assisting teachers needs to be empowering and one that builds capacity and develops confidence in their ability to adopt new skills and roles within the school environment and in their community. Programme monitoring requires a balance of accurately recording observed behaviour of teachers, but which also gives them support and encouragement.

\section{REFERENCES}

1. Mayosi BM, Flisher AJ, Lalloo UG, Sitas F, Tollman SM, Bradshaw D. The burden of non-communicable diseases in South Africa. Lancet 2009;374(9693):934-947.

2. Kruger HS, Puoane T, Senekal M, van der Merwe MT. Obesity in South Africa: challenges for government and health professionals. Public Health Nutr 2005;8(5):491-500.

3. Joubert J, Norman R, Lambert EV, et al. Estimating the burden of disease attributable to physical inactivity in South Africa in 2000. S Afr Med J 2007;97(8 Pt 2):725-731.

4. Steyn K, Levitt NS, Hoffman M, et al. The global cardiovascular diseases risk pattern in a peri-urban working-class community in South Africa. The Mamre study. Ethn Dis 2004;14(2):233-242.

5. Haskell WL, Blair SN, Hill JO. Physical activity: Health outcomes and importance for public health policy. Prev Med 2009;49(4):280-282.

6. Amosun SL, Reddy PS, Kambaran N, Omardien R. Are students in public high schools in South Africa physically active? Outcome of the 1st South African National Youth Risk Behaviour Survey. Can J Public Health 2007;98(4):254-258.

7. Naylor PJ, Macdonald HM, Zebedee JA, Reed KE, McKay HA. Lessons learned from Action Schools! BC - an 'active school' model to promote physical activity in elementary schools. J Sci Med Sport 2006;9(5):413423.

8. Franks AL, Kelder SH, Dino GA, et al. School-based programs: lessons learned from CATCH, Planet Health, and Not-On-Tobacco. Prev Chronic Dis 2007;4(2):A33

9. Boyle SE, Jones GL, Walters SJ. Physical activity among adolescents and barriers to delivering physical education in Cornwall and Lancashire, UK: a qualitative study of heads of PE and heads of schools. BMC Public Health 2008;8:273.

10. Cale L. Physical activity promotion in schools: PE teachers' views. Phys Educ Sport Pedagog 2000;5(2):158-168.

11. Draper CE, Kolbe-Alexander TL, Lambert EV. A retrospective evaluation of a community-based physical activity health promotion programme. $J$ Phys Act Health 2009;6(5):578-588.

12. Richards R, O'Leary B, Mutsonziwa K. Measuring quality of life in informal settlements in South Africa. Soc Indic Res 2007;81(2):375-388.

13. Background information for the PPT Pilots Project in Southern Africa. Available at: http://www.pptpilot.org.za/Alexandra_Township.pdf. Accessed August 27, 2009.

14. van Mechelen W, van Lier WH, Hlobil H, Crolla I, Kemper HCG. Eurofit: handleiding met referentieschalen voor 12- tot en met 16-jarige jongens en meisjes in Nederland. Haarlem: Uitgeverij de Vrieseborch; 1991.

15. Armstrong MEG. Youth fitness testing in South African primary school children: national normative data, fitness and fatness, and effects of socioeconomic status. PhD thesis, University of Cape Town, June, 2009.

16. Gittelsohn J, Merkle A, Story M, et al. School climate and implementation of the Pathways study. Prev Med 2003;37(6 Pt 2):S97-S106.

17. Morgan PJ, Hansen V. Classroom teachers' perceptions of the impact of barriers to teaching physical education on the quality of physical education programs. Res Q Exercise Sport 2008;79(4):506-516.

18. Carrel AL, McVean JJ, Clark RR, Peterson SE, Eickoff JC, Allen DB. School-based exercise improves fitness, body composition, insulin sensitivity, and markers of inflammation in non-obese children. J Pediatr Endocrinol Metab 2009;22(5):409-415.

19. Christodoulos AD, Douda HT, Polykratis M, Tokmakidis SP. Attitudes towards exercise and physical activity behaviours in Greek schoolchildren after a year long health education intervention. $\mathrm{Br} J$ Sports Med 2006;40(4):367-371.

20. Caballero B, Clay T, Davis SM, et al. Pathways: a school-based, randomized controlled trial for the prevention of obesity in American Indian schoolchildren. Am J Clin Nutr 2003;78(5):1030-1038. 